\title{
Low-temperature graphitization of amorphous carbon nanospheres
}

\author{
Katia Barbera ${ }^{a}, *$, Leone Frusteri a ${ }^{a}$ Giuseppe Italiano ${ }^{b}$, Lorenzo Spadaro $^{c}$, Francesco Frusteri $^{c}$, \\ Siglinda Perathoner ${ }^{\text {, }}$ Gabriele Centi ${ }^{a}$ \\ a University of Messina and INSTM/CASPE (Lab. of Catalysis for Sustainable Production and Energy), Department of Electronic Engineering, Industrial \\ Chemistry and Engineering - Contrada di Dio I-98166 Messina, Italy \\ b Eco-Rigen S.r.l. R\&D - Contrada Piana del Signore c/o Raffineria di Gela, I-93012 Gela (CL), Italy \\ "Institute of Advanced Technologies for Energy "Nicola Giordano" (ITAE), Department of Energy and Transport (DET), National Council of Research \\ (CNR) - Salita S. Lucia sopra Contesse 5 I-98126, Messina, Italy
}

\section{A R T I C L E I N F O}

Article history:

Received 20 March 2014

Accepted 9 April 2014

Published 20 June 2014

Keywords:

Graphitization

Carbon nanospheres

Carbon structural disorder

\begin{abstract}
A B S T R A C T
The investigation by SEM/TEM, porosity, and X-ray diffraction measurements of the graphitization process starting from amorphous carbon nanospheres, prepared by glucose carbonization, is reported. Aspects studied are the annealing temperature in the $750-1000{ }^{\circ} \mathrm{C}$ range, the type of inert carrier gas, and time of treatment in the 2-6 h range. It is investigated how these parameters influence the structural and morphological characteristics of the carbon materials obtained as well as their nanostructure. It is shown that it is possible to maintain after graphitization the round-shaped macro morphology, a high surface area and porosity, and especially a large structural disorder in the graphitic layers stacking, with the presence of rather small ordered domains. These are characteristics interesting for various catalytic applications. The key in obtaining these characteristics is the thermal treatment in a flow of $\mathrm{N}_{2}$. It was demonstrated that the use of He rather than $\mathrm{N}_{2}$ does not allow obtaining the same results. The effect is attributed to the presence of traces of oxygen, enough to create the presence of oxygen functional groups on the surface temperatures higher than $750{ }^{\circ} \mathrm{C}$, when graphitization occurs. These oxygen functional groups favor the graphitization process.
\end{abstract}

(c) 2014, Dalian Institute of Chemical Physics, Chinese Academy of Sciences. Published by Elsevier B.V. All rights reserved.

\section{Introduction}

Nanocarbons (also indicated as nano-structured carbons) indicate carbon materials having a tailored nanoscale dimension and functional properties critically depending on their nano-scale features and architecture [1-13]. The role of the nanostructure in determining the performance and catalytic behavior of carbon materials is well known $[1,14,15]$, and thus these materials open interesting opportunities for catalysis.

Nanocarbons include many different types of carbon mate- rials such as nano-fibers, -coils, -diamond, -horns, -onion, fullerene, etc. They find increasing interests as catalysts and may be actually considered as a novel class of catalytic materials. The range of applications goes from electrocatalysis (being a conductive support) and photocatalysis to novel supports for metal particles (for applications going from environmental protection to catalytic syntheses). In addition, their use as metal-free catalysts or electrocatalysts (related to the specific type of active sites present on the surface of the nanocarbon, as consequence of defects, doping and surface treatments) was

\footnotetext{
* Corresponding author. Tel: +39-090-6765607; Fax: +39-090-391518; E-mail: kbarbera@unime.it

This work was supported by EU project INCAS "Integration of Nanoreactor and multisite CAtalysis for a Sustainable chemical production" (Grant agreement no: 245988), in the frame of which part of this work was realized.

DOI: 10.1016/S1872-2067(14)60098-X | http://www.sciencedirect.com/science/journal/18722067 | Chin. J. Catal., Vol. 35, No. 6, June 2014
} 
shown to offer new exciting possibilities [16-21].

Their catalytic properties derive from their unique combination of chemical properties, inferred by $\mathrm{sp}, \mathrm{sp}^{2}$, and $\mathrm{sp}^{3}$ hybridized bonds, with the several structural arrangements, i.e. linear, planar, or tetrahedrical geometries [22]. Metal-free nanocarbons show interesting catalytic properties in various reactions, going from alkane activation and oxidative dehydrogenation [23-25] to the selective gas-phase oxidation of acrolein to acrylic acid [26].

In the latter reaction, for example, the $\mathrm{sp}^{2}$ carbon acts as a bifunctional catalyst: the nucleophilic oxygen atoms terminating the graphite (0001) surface abstract the formyl hydrogen and the activated aldehyde gets oxidized by epoxide-type mobile oxygens. In general, for $\mathrm{sp}^{2}$ nanocarbons, high-energy sites provided by the dangling bond of the $\mathrm{sp}^{2}$ hybridization are located at the edges (prismatic sites). These sites are saturated by heteroatoms (depending on the pre-treatment), providing a rich surface catalytic reactivity for both acid-base and redox chemistry. If the graphitic sheets contain defects in form of pentagonal, heptagonal, or larger non-hexagonal units, an additional charge present can assist the activation or dissociation of adsorbing molecules. In addition, if the graphitic sheets are curled, then the strain on the $\mathrm{sp}^{2}$ centers leads to charge localization and increases the poor reactivity of the basal plane.

The nanostructure, type of surface species, and hybridization of surface carbon atoms, which may be enhanced from the presence of strains and curvatures as well as degree of graphitization, are all aspects determining the catalytic performance. An example is the synthesis of phosgene, which is still produced using carbon as industrial catalyst in an annual amount of about 5-6 million tons, in spite of the well-known safety issues (high toxicity of the products and hazardous reaction conditions) [27]. Phosgene is a chemical intermediate used in the manufacture of important industrial products such as polyurethanes, polycarbonates, pharmaceuticals, and agrochemicals. Metal-free carbon catalysts show better performance than other materials, but the specific nature of the carbon strongly influences the performance [28], although the exact nature of the active sites is still unknown. In fact, $\mathrm{Cl}_{2}$ dissociation and further $\mathrm{CO}$ halogenation are probably the first steps in the reaction of phosgene synthesis from $\mathrm{CO}$ and $\mathrm{Cl}_{2}$, and it is known that reaction mechanism considerably depends on the nanocarbon stucture [29].

In addition to specific nanostructure properties, the carbon-based catalysts should possess porosity characteristics different from those necessary in other relevant areas of application of carbon materials (i.e. sorption, molecular separations, and gas storage), because microporosity may reduce catalyst effectiveness. Mass transport, particularly in fast reactions, can significantly limit the reaction rate, but equally relevant, in strongly exothermic reactions, is heat transport, which may result detrimental not only in catalytic performance (especially selectivity), but also in long-term stability of the carbon catalyst. The degree of graphitization is a way to improve heat transfer and control surface reactivity. For this reason, the specific nanostructure and surface nature of carbon catalysts play a specific role in their performance for phosgene synthesis [28].
Carbon nanospheres are a novel type of nanocarbon materials, which attracted interest for the presence of different hybridized bond surface sites and of curling planes, which may change the reactivity of graphitic sheets. Several papers have been published on these materials, for applications going from manufacture of electrodes to catalysis [30-38], showing how the graphitization degree of the carbon plays an important role in determining its properties. Nevertheless, a key issue is to avoid the destruction of the other important characteristics for reactivity, such as porosity and type of surface species (related to hybridized bond surface sites, defects, etc.).

Usually, the graphitization process is made by applying high current densities or temperatures $\left(>2500{ }^{\circ} \mathrm{C}\right)$ [39-41]. Apart the need to use a proper graphitizable carbon precursor such as CNF $[42,43]$, the main disadvantages of these processes are the high energy consumption, the low yield, and the surface area loss. There is also a change in the characteristic nanostructure. Briston et al. [44], for example, have analyzed the transformation of amorphous porous carbon nanospheres under Joule heating, observing significant carbon ordering resulting in the formation of a 3D network of buckled graphitic sheets. The peculiar carbon reactivity characteristics are thus lost in the process.

Hence, some attempts have been made in order to graphitize carbon at relatively low temperature $\left(<1000^{\circ} \mathrm{C}\right)$ by means of metals ( $\mathrm{Fe}, \mathrm{Co}, \mathrm{Ni}$, etc.), which accelerate the initiation $[45,46]$. Despite the wide application of these methodologies, the encapsulation of such metals into the framework leads to the need of further purification steps.

Therefore, in this work we discuss a method to graphitize amorphous carbon nanospheres, obtained by hydrothermal decomposition of glucose, without using metals and with a procedure allowing to maintain high the surface area minimizing changes in the surface nanostructure. The goal is to obtain a crystalline arrangement with onion-like structure, without surface area loss. We investigated here the role of the main experimental parameters in the treatment (annealing temperature at 750 or $1000{ }^{\circ} \mathrm{C}$, type of inert carrier gas, time of stream in the 2-6 h range) and how they influence the morphological characteristics of the carbon materials obtained as well as their nanostructure.

\section{Experimental}

\subsection{Amorphous carbon synthesis}

Pure glucose (10 wt\%) was dissolved in $180 \mathrm{~mL}$ of distilled water to form a clear solution and placed in a Teflon-sealed autoclave at $200{ }^{\circ} \mathrm{C}$ for $20 \mathrm{~h}$. The product was then separated by filtration and washed several times with hot water, acetone, and ethanol solvents. Then it was dried at $100{ }^{\circ} \mathrm{C}$ and further treated at $200{ }^{\circ} \mathrm{C}$ for $2 \mathrm{~h}$. The quantitative yield was about 20 wt $\%$. This sample is indicated as CHT.

\subsection{Graphitization procedure}

For each graphitization procedure, ca. $200 \mathrm{mg}$ of CHT were 
put in a vertical fixed bed reactor, as schematically shown in Fig. 1. In each experiment, only a single parameter was changed, i.e., annealing temperature $\left(750\right.$ or $\left.1000^{\circ} \mathrm{C}\right)$, isotherm time on stream (2 or $6 \mathrm{~h}$ ), or carrier of He or $\mathrm{N}_{2}$ gas flow (100 $\mathrm{STP} \mathrm{mL} / \mathrm{min}$ ). For the more prominent sample, the concentration of oxygen in $\mathrm{N}_{2}$ stream and the evolution of gases $\left(\mathrm{CO}_{2}\right.$, $\mathrm{H}_{2} \mathrm{O}$ ) during annealing treatment was followed by use of a Hyden Mass Spectrometer HP 2-N, operating in SEM mode. The samples were indicated as $\mathrm{X}-\mathrm{Y}-\mathrm{Z}$, where $\mathrm{X}$ is type of carrier gas $\left(\mathrm{He}\right.$ or $\mathrm{N}_{2}$ ), $\mathrm{Y}$ the reaction temperature $\left({ }^{\circ} \mathrm{C}\right)$, and $\mathrm{Z}$ the isotherm time on stream.

\subsection{Carbon characterization}

Samples were characterized by X-ray powder diffraction (XRD) using a Philips X-Pert diffractometer with a monochromatic $\mathrm{Cu} K_{\alpha}(\lambda=1.54056 \AA)$ radiation at $40 \mathrm{kV}$ and $30 \mathrm{~mA}$. Data were collected over a $2 \theta$ range of $10^{\circ}-100^{\circ}$, with a step size of $0.04^{\circ}$ at a time per step of 3s. The morphology of the samples was investigated by scanning electron microscopy (SEM) using a Philips XL-30-FEG SEM at an accelerating voltage of $5 \mathrm{kV}$. To improve the quality of images, the samples were previously treated with $\mathrm{Au}$ using a gold sputter coater device. For elemental analysis, the energy dispersive X-ray (EDX) analyzer was employed by using not pre-treated samples. Carbon morphology structure was also investigated by transmission electron microscopy (TEM) using a Philips CM12 microscope (resolution $0.2 \mathrm{~nm}$ ), provided with a high resolution camera, at an accelerating voltage of $120 \mathrm{kV}$. Suitable specimens for TEM analyses were prepared by ultrasonic dispersion in $i$-propyl alcohol adding a drop of the resulting suspension onto a holey carbon supported grid. The surface areas were calculated from BET equation from the adsorption branch of the isotherms, obtained at $-196{ }^{\circ} \mathrm{C}$ on a Quantachrome sorption analyzer. Prior to the measurements, samples were heated in $\mathrm{N}_{2}$ flow at 350 ${ }^{\circ} \mathrm{C}$ for $1 \mathrm{~h}$. The micropore area and volume were evaluated by the $t$-plot method.

Raman spectra were recorded by using a Renishaw Raman Microscope spectrometer. An $\mathrm{Ar}^{+}$laser emitting at $514 \mathrm{~nm}$ was used, in which the output power was limited in order to avoid

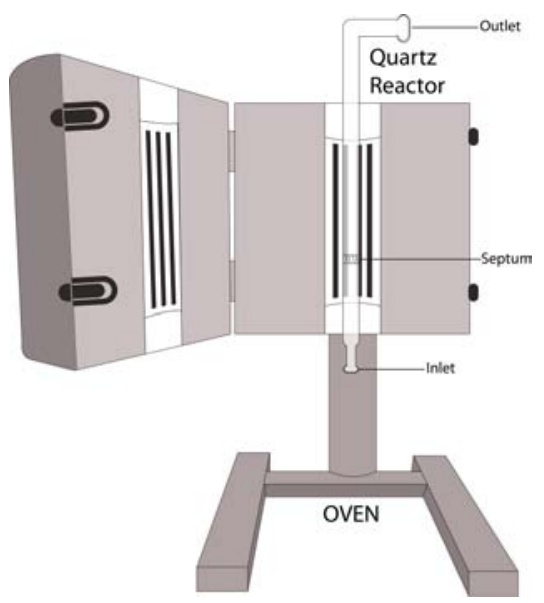

Fig. 1. Schematic drawing of the apparatus used for graphitization procedure. sample damage. The photons scattered by the sample were dispersed by a 1800 lines/mm grating monochromator and simultaneously collected on a CCD camera; the collection optic was set at $50 \times$ objective. The spectra were obtained by collecting 30 acquisitions (each of $20 \mathrm{~s}$ ) on a powdered sample in air.

FT-IR spectra were collected on powder samples diluted in $\mathrm{KBr}(1: 1)$ at $4 \mathrm{~cm}^{-1}$ resolution, using an Equinox 55 spectrometer equipped with an MCT detector and an environmental channel operating in diffuse reflectance mode. Prior to spectra collection at r.t., a thermal treatment of the samples at $150{ }^{\circ} \mathrm{C}$ in Ar flow (20 STP mL/min) was carried out.

X-ray photoelectron spectroscopy (XPS) data were obtained using a Physical Electronics GMBH PHI 5800-01 spectrometer operating with a monochromatized $\mathrm{Al}-K_{\alpha}$ radiation with a power beam of $300 \mathrm{~W}$. The pass energy for determination of the oxidation state and concentration of surface species was 11.0 and $58.0 \mathrm{eV}$, respectively. The BE regions of $\mathrm{C} 1 s$ (280-300 $\mathrm{eV}$ ) and $\mathrm{O} 1 s(524-544 \mathrm{eV})$ were investigated, taking the $\mathrm{Al} 2 p$ line $(73.0 \mathrm{eV})$ of aluminum standard as reference for signal calibration. $\mathrm{Ar}^{+} 2 \mathrm{~kW}$ small beam sputtering was performed in order to remove adventious carbon.

\section{Results and discussion}

\subsection{Surface-initiated ordering}

SEM/TEM images of CHT samples before and after graphitization are shown in Fig. 2. It is noticeable that by hydrothermal synthesis it is possible to obtain spherical carbon particles, with main diameter in the $200-400 \mathrm{~nm}$ range, but also the presence of larger ones can be detected (Figs. 2(a) and (b)). This distribution is probably due to the reaction conditions, i.e. the absence of an homogeneous mixing during the synthesis. Nevertheless, this hydrothermal procedure allows to obtain morphologically more uniform carbon particles with respect to carbon particles obtained by hydrocarbon pirolysis, as reported in Ref. [47]. After all the different investigated thermal treatments, the spherical shape and morphology were retained although some differences in the ordering degree can be noted.

After the less severe treatment $\left(\mathrm{N}_{2}-750-2 \mathrm{~h}\right.$, Fig. 2(c)) no indication of ordering is observed, while for the samples treated in $\mathrm{N}_{2}$ at $1000{ }^{\circ} \mathrm{C}$ the graphitization of a fraction of amorphous carbon takes place as a function of time on stream, resulting in the formation of a certain amount of a more ordered carbon (Figs. 2(d) and (e)).

This type of carbon is graphitic like, with a characteristic nano-onion carbon structure at the surface. In our previous works and as confirmed by Nieto-Márquez [47,48], we concluded that the rearrangement initiates at the particle surface and propagates inside by forming concentric shells of $\mathrm{C}$ $\mathrm{sp}^{2}$-bonded atoms from the spherical or cylindrical shape of the original amorphous precursor.

This process is thermodynamically driven but is influenced also by the presence of surface functional groups on carbons, which depend on the temperature and type of precursor during the carbonization stage. In our CHT sample, obtained from glu- 

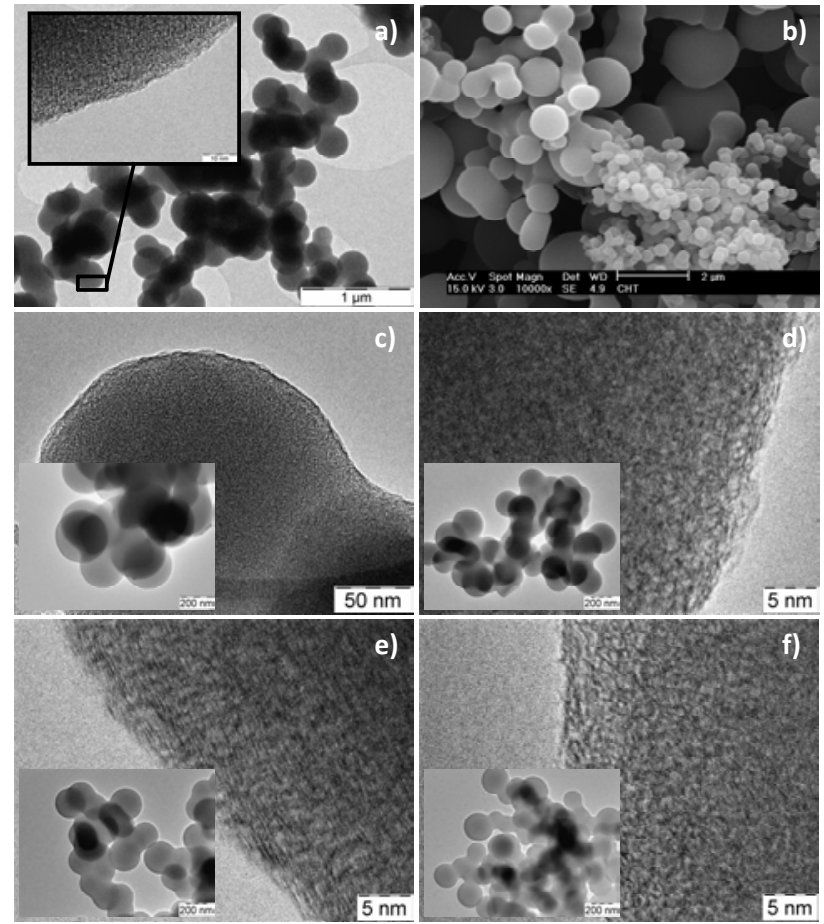

Fig. 2. Micrographs of starting CHT amorphous carbon (a and b) and after different heating treatment (c-f). (c) $\mathrm{N}_{2}-750-2 \mathrm{~h}$; (d) $\mathrm{N}_{2}-1000-2 \mathrm{~h}$; (e) $\mathrm{N}_{2}-1000-6 h ;$ (f) He-1000-6h.

cose carbonization in mild conditions $\left(200{ }^{\circ} \mathrm{C}\right)$, the $\mathrm{O}_{2}$ content, estimated by EDX, is about 10 at\%. As it is known $[1,49,50]$, the annealing process leads to both a dramatic reduction in the oxygen amount and the modification in the distribution of oxygen species towards the more thermally stable ones, such as anhydride and lactone groups, with both $\mathrm{H}_{2} \mathrm{O}$ and $\mathrm{CO}_{2}$ release due to this arrangement (Fig. 3).

In fact, at temperatures above $750{ }^{\circ} \mathrm{C}$, when graphitization starts to occur, the amount of surface oxygen species is reduced. As confirmed in Fig. 3, the presence of small traces of oxygen in the inert stream (less than 0.01 vol\%) plays an important role in maintaining these species, and at the same time preventing the possibility of combustion of carbon. This ex-

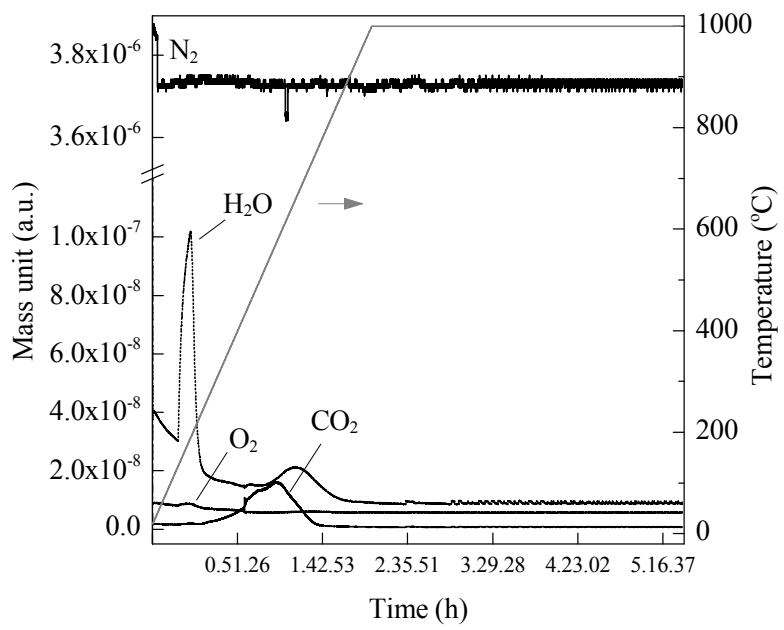

Fig. 3. MS profiles of gases in the outlet stream for $\mathrm{N}_{2}-1000-6 \mathrm{~h}$. plains why the treatment in $\mathrm{N}_{2}$ at $1000{ }^{\circ} \mathrm{C}$ allows the graphitization of the sample, with a carbon yield of $70 \mathrm{wt} \%$, while the same effect is absent when He is used as carrier under the same conditions (Fig. 2(f); $1000^{\circ} \mathrm{C}, 6 \mathrm{~h}$ ).

\subsection{Development of microporosity in graphitized carbon}

The nitrogen sorption isotherms for the CHT samples after different annealing treatments are shown in Fig. 4. All samples gave rise to type II nitrogen gas sorption isotherms, according to IUPAC classifications, with typical $\mathrm{H}_{4}$ hysteresis loops, generally observed in complex materials containing both micropores and mesopores, and a characteristic step-down in the desorption branch associated to the hysteresis loop closure.

The filling of the narrow micropores takes place at low relative pressures (at $p / p_{0}<0.01$ ). This process has been termed "primary micropore filling", while filling of the wider micropores may occur over a broader range of relative pressure $\left(p / p_{0} \approx 0.01-0.2\right)$ [51]. Additionally, the slight rise of $\mathrm{N}_{2}$ uptake in the adsorption isotherms at higher relative pressures, $p / p_{0}>$ 0.8 , indicates that only a slight contribution of inter particle porosity associated with the meso- and macrostructures of the sample are present [52].

Surface areas (S.A.), pore volumes, and average pore sizes are summarized in Table 1. It is noticeable that the CHT sample has a very high surface area $\left(635 \mathrm{~m}^{2} / \mathrm{g}\right)$ with a high contribution of the micropore fraction $\left(503 \mathrm{~m}^{2} / \mathrm{g}\right)$. Upon $\mathrm{N}_{2}$ treatment at $1000{ }^{\circ} \mathrm{C}$ for $2 \mathrm{~h}$, the S.A. decreases (about -28\%) with a contemporaneous relative increase of microporosity from the original $80 \%$ in the starting sample to about $88 \%$ in the samples after $2 \mathrm{~h}$ of treatment at $1000{ }^{\circ} \mathrm{C}$. This suggests that essentially a sintering process occurs up to $2 \mathrm{~h}$. For longer times on stream $(6 \mathrm{~h})$ at $1000{ }^{\circ} \mathrm{C}$, the situation is different. There is an increase both in S.A. (further $+28 \%$ with respect to the sample after $2 \mathrm{~h}$ ) and microporosity (about 95\% of the whole porosity). This is consistent with the observed reorganization due to graphitization discussed before, which occurs together with the loss of less stable carbon species present in the amorphous

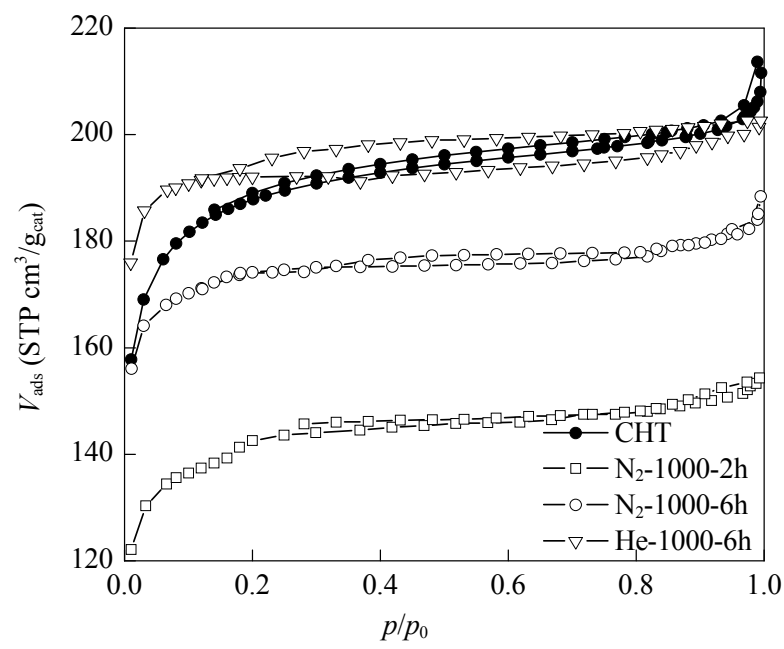

Fig. 4. Nitrogen sorption isotherms of the graphitized samples obtained using amorphous $\mathrm{CHT}$ at $1000{ }^{\circ} \mathrm{C}$ and different graphitization time on streams and carrier gas. 
Table 1

Textural properties of the graphitized samples obtained using amorphous $\mathrm{CHT}$ at $1000^{\circ} \mathrm{C}$ at different graphitization time on streams.

\begin{tabular}{lccccc}
\hline Sample & S.A. BET-Lang ${ }\left(\mathrm{m}^{2} / \mathrm{g}_{\text {cat }}\right)$ & Micropore area $^{\mathrm{b}}\left(\mathrm{m}^{2} / \mathrm{g}_{\text {cat }}\right)$ & P.V. $\left(\mathrm{cm}^{3} / \mathrm{g}_{\text {cat }}\right)$ & Micropore vol. b & A.P.D. $(\AA)$ \\
\hline CHT & $635-840$ & 503 & 0.31 & 0.23 & 20 \\
$\mathrm{~N}_{2}-1000-2 \mathrm{~h}$ & $456-603$ & 400 & 0.20 & 0.19 & 27 \\
$\mathrm{~N}_{2}-1000-6 \mathrm{~h}$ & $585-770$ & 553 & 0.26 & 0.26 & 15 \\
$\mathrm{He}-1000-6 \mathrm{~h}$ & $632-833$ & 507 & 0.29 & 0.23 & 20 \\
\hline
\end{tabular}

a Calculated using BET-Langmuir methods.

${ }^{\mathrm{b}}$ Calculated by the $t$-plot method.

carbon (as typically occurs in preparing activated carbons). In agreement, the treatment in He instead of $\mathrm{N}_{2}$ at $1000^{\circ} \mathrm{C}$ for $6 \mathrm{~h}$ (Table 1) leads to a similar S.A. of the starting sample, as well as similar fraction of microporosity (about 80\%).

In principle, some interstitial $\mathrm{N}$ atoms in the carbon structure may form during the annealing process at $1000{ }^{\circ} \mathrm{C}$ in the presence of $\mathrm{N}_{2}$ (although we have no metals in our sample prepared from pure glucose). Antonov et al. [53] observed that differently from nitrogen atoms substituting carbon atoms, which hardly move at $750{ }^{\circ} \mathrm{C}$, interstitial nitrogen atoms are mobile during annealing at high temperature. This process may decrease the activation energy to initialize the graphitization process, according to Norfolk et al. [54]. However, we believe that this is an unlikely mechanism because it requires to dissociate $\mathrm{N}_{2}$. It is thus more reasonable that the difference in the behavior is associated with the presence of traces of oxygen in the $\mathrm{N}_{2}$ flow, which modifies the amount of oxygen functional groups during the high temperature annealing (see Fig. 3). This different surface situation is responsible for the easier graphitization in the presence of $\mathrm{N}_{2}$ rather than He.

\subsection{Evolution of structural ordering}

$\mathrm{XRD}$ is widely used for the microstructural characterization of carbon materials by peak profile analysis [55]. Figure 5 shows the XRD patterns for the starting sample (CHT) and those treated at $1000{ }^{\circ} \mathrm{C}$ in $\mathrm{N}_{2}(2$ and $6 \mathrm{~h}$ ) and He $(6 \mathrm{~h})$. It is confirmed that the use of $\mathrm{N}_{2}$ instead of $\mathrm{He}$ as carrier gas during the thermal treatment favors the graphitization, which is instead nearly absent in the case of He. Elaboration of these XRD patterns, after correction for background baseline and instrumental broadening, allows to estimate the average values of the interlayer spacing $d_{002}$, the height of layered stacking $\left(L_{c}\right)$, and the basal plane length $\left(L_{\mathrm{a}}\right)$. The above parameters were used to estimate their graphitic structural order. The average interlayer spacing is measured through the position of the (002) peak by applying the Bragg's equation. The height of layered stacking is estimated from the (002) and (110) peaks using the Scherrer's formula. The layer dimension in the plane of the layer can be calculated from the peak width at half of the maximum intensity $(B)$ in the formulas $L_{\mathrm{a}}=1.84 \lambda / B \cos \theta$ [55] and $L_{\mathrm{c}}$ $=0.89 \lambda / B \cos \theta$. Notice that the peaks of the two-dimensional lattice (100) reflections are displaced toward higher angle $\left(46^{\circ}\right.$ rather than $43^{\circ}$ ) [56]. The absolute value of this displacement is greater the smaller the layer dimension $L_{a}$, i.e. the effective dimension of the graphite layers in the plane of the layer. The peaks are also rather broad. Both these aspects are consistent with the presence of large structural disorder in the graphitic layers stacking, in agreement with micrograph indications.

Table 2 summarizes the lattice values for the two $\mathrm{N}_{2}$-treated samples, e.g. of the two samples for which we have evidence of graphitization. They show an increase in the intensities of the (002) and (110) reflections, proportional to the time on stream of the thermal treatment. For both samples, the calculated $d_{002}$ spacing are 0.357 and $0.349 \mathrm{~nm}$, respectively, slightly higher than for pure graphite $(0.335 \mathrm{~nm})$, suggesting the incipient, but not complete, formation of a graphitic layer. Note that, for example, for carbon graphitic materials after ball milling, an increase of the $d_{002}$ spacing from $0.335 \mathrm{~nm}$ to $0.360-0.370 \mathrm{~nm}$ has been observed, proportionally to the time of ball milling. The data in Table 2 thus indicate that the sample treated at $1000{ }^{\circ} \mathrm{C}$ in $\mathrm{N}_{2}$ for $2 \mathrm{~h}$ shows a large amount of faulted stacking layers, and that this amount decreases after $6 \mathrm{~h}$, although still remaining not-negligible.

The values of $L_{\mathrm{a}}$ and $L_{\mathrm{c}}$ give, on the contrary, an indication of the ordered graphitic regions. The effective dimension $L$ of the graphitic microcrystallites can be determined as follows: $L=$ $\left(\pi / 4 \cdot L_{\mathrm{a}}{ }^{2} \cdot L_{c}\right)^{1 / 3}[57]$. The values obtained for the two analyzed

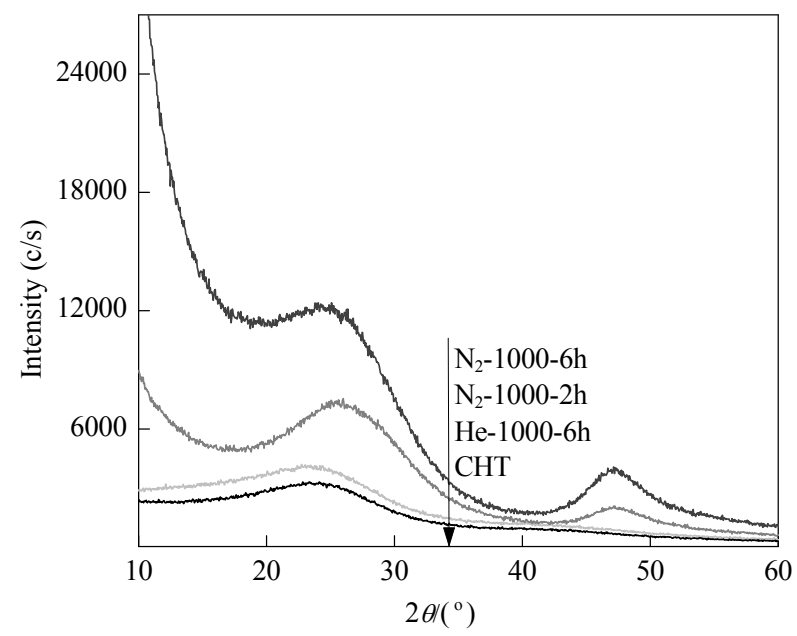

Fig. 5. XRD patterns of CHT and samples annealed at $1000{ }^{\circ} \mathrm{C}$ in $\mathrm{N}_{2}$ or $\mathrm{He}$, in the $2 \theta$ range $10^{\circ}-60^{\circ}$. The (002) and (110) planes of the graphitic framework correspond to $2 \theta=26^{\circ}$ and $46^{\circ}$, respectively.

\section{Table 2}

Lattice properties (from XRD measurements) of graphitized samples for the two $\mathrm{N}_{2}$-treated samples.

\begin{tabular}{lccc}
\hline Sample & $d_{002}(\mathrm{~nm})$ & $L_{\mathrm{a}}(\mathrm{nm})$ & $L_{\mathrm{c}}(\mathrm{nm})$ \\
\hline $\mathrm{N}_{2}-1000-2 \mathrm{~h}$ & 0.357 & 5.4 & 0.94 \\
$\mathrm{~N}_{2}-1000-6 \mathrm{~h}$ & 0.349 & 4.5 & 0.99 \\
\hline
\end{tabular}


samples, 2.4 and $2.56 \mathrm{~nm}$, indicate the presence of rather small ordered domains, suggesting the very large orientational disorder of the graphite planes, an aspect essential for enhancing the reactivity of these materials and explaining the reason of maintaining a high surface area and porosity even for severe annealing procedures $\left(1000^{\circ} \mathrm{C}, 6 \mathrm{~h}\right)$.

More prominent highlights of crystalline and amorphous features of CHT, and those treated in He or $\mathrm{N}_{2}$ under the same conditions are also extracted by vibrational spectroscopies, such as Raman and infrared (Fig. 6(a) and (b), respectively). Concerning the Raman spectra, for the CHT sample a reasonable signal-to-noise ratio is hardly achieved, having carbon a broad fluorescence background [58,59], caused by its organic nature, impurities, and surface defects, which obscured the spectrum. For the other two samples, two main features appear at 1586 and $1344 \mathrm{~cm}^{-1}$, respectively, changing the relative intensities into the different samples [60]. In particular, the $G$ peak around $1580-1600 \mathrm{~cm}^{-1}$ and the $D$ peak around 1350 $\mathrm{cm}^{-1}$ usually are assigned to zone center phonons of $\mathrm{E}_{2 \mathrm{~g}}$ symmetry and K-point phonons of $A_{1 g}$ symmetry, respectively. In general, they can be attributed to many forms of $\mathrm{sp}^{2}$-bonded carbons with various degrees of graphitic ordering, ranging from microcrystalline graphite to amorphous carbon [61], because in general this latter can also have any mixture of $\mathrm{sp}^{3}, \mathrm{sp}^{2}$, and even $\mathrm{sp}^{1}$ sites. However, while the $G$ peak involves the in-plane bond-stretching motion of pairs of $\mathrm{C} \mathrm{sp}^{2}$ atoms, and not necessarily in the presence of six fold rings, but in general of at all $\mathrm{sp}^{2}$ sites, the $D$ peak is forbidden in perfect graphite and becomes active in the presence of more disordered structure $[60,61]$. Therefore, what is more relevant is the intensity ratio between the two bands $\left(I_{\mathrm{D}} / I_{\mathrm{G}}\right)$ that allows to determine the relative order degree. In the case of $\mathrm{N}_{2}-100-6 \mathrm{~h}$, the $I_{\mathrm{D}} / I_{\mathrm{G}}$ is equal to 0.77 , while this value increases for He-100-6h (0.97), associated with an increase of disorder. According to the TK model, which implies the correlation occurring between this ratio and $L_{\mathrm{a}}$ value obtained from XRD measurement to evaluate the size of graphite cluster size, our values lie within the range where $I_{\mathrm{D}} / I_{\mathrm{G}}$ is $\alpha 1 / L_{\mathrm{a}}$, i.e. in the crystalline range [60].

Figure 6(b) shows the FT-IR spectra recorded on CHT and $\mathrm{N}_{2}-1000-6 \mathrm{~h}$ samples. The IR spectrum of CHT belongs from either the absence of symmetry in amorphous carbon or the higher $\mathrm{sp}^{2}$ content in the network [61]. A broad band ranging from 3800 to $3000 \mathrm{~cm}^{-1}$ is dominated by H-related bands. Very intense features at $1744 \mathrm{~cm}^{-1}$ appear, assigned to the stretching of $\mathrm{C}=\mathrm{O}$ belonging to the oxygen contamination, and bands at 1434 and $1280 \mathrm{~cm}^{-1}$ are assigned to $\mathrm{C}-\mathrm{C}$ skeleton and $\mathrm{CH}_{2}$ bending modes [62]. Finally, a band at $1626 \mathrm{~cm}^{-1}$ could represent the bending mode of $\mathrm{H}_{2} \mathrm{O}$ present in the material, which is not desorbed at the treatment temperature. Upon $\mathrm{N}_{2}$ treatment, the spectrum changes significantly. In the 3800 to $3000 \mathrm{~cm}^{-1}$ region, a main peak centered at $3300 \mathrm{~cm}^{-1}$ is present, which is univocally assigned to $\mathrm{N}-\mathrm{H}$ stretching mode. The features of carbonyl groups are still detectable, with less extent and slightly red-shifted $\left(1670 \mathrm{~cm}^{-1}\right)$, due to conjugation effects $[61,63]$, as well as the $\mathrm{C}-\mathrm{H}$ features.

Finally, in order verify the presence of oxygen functionalities in both CHT and annealed sample, the C $1 s$ and $01 s$ XPS spectra of CHT and $\mathrm{N}_{2}-1000-6 \mathrm{~h}$ samples were compared. The changes in $\mathrm{C} 1 s$ spectrum are shown in Fig. 7(a). The CHT sample presents a right shoulder in comparison with the sharp and symmetric graphitic C $1 s$ peak present for $\mathrm{N}_{2}-1000-6 \mathrm{~h}$, reasonably due to the presence of functional $\mathrm{C}-\mathrm{OH}, \mathrm{C}=\mathrm{O}$, and $\mathrm{COOH}$ groups [64], as already shown. The same trend is observed for the $01 s$ (Fig. 7(b)) peaks, which present a feature centered at $530.03 \mathrm{eV}$ representing that one strongly C-bonded, and a right shoulder due to oxygen functionalities, which are evacuated during treatment in form of $\mathrm{CO}_{2}$ or $\mathrm{H}_{2} \mathrm{O}$ (see Fig. 3).

Finally, the quantitative analysis of the $\mathrm{O}_{1 \mathrm{~s}}$ and $\mathrm{C}_{1 \mathrm{~s}}$ relative abundance $s$ is reported in Table 3. It is clearly visible that CHT presents the majority of carbon, with an oxygen content in agreement with that calculated by EDX. Upon $\mathrm{N}_{2}$ annealing, the surface oxygen is reduced (about 35\%), as a consequence of the rearrangement of the surface functionalities leading to a partial $\mathrm{CO}_{2}$ removal. However, the still existence of oxygen into the surface would suggest that these species are those stabilized by strong interaction with carbon.

\section{Conclusions}

The results presented here indicate the possibility to graphitize amorphous carbon nanospheres, prepared by glucose carbonization, maintaining the round-shaped macro morphology, a high surface area and porosity, and especially a large structural disorder in the graphitic layers stacking, with the
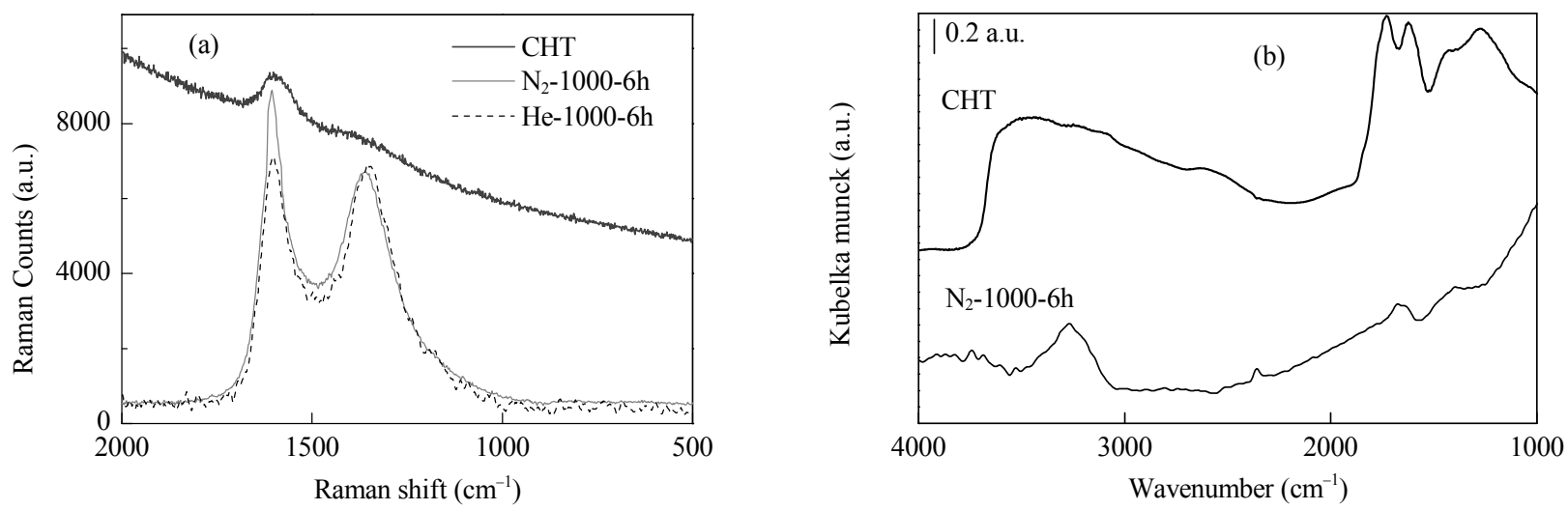

Fig. 6. (a) Raman spectra acquired in CHT, $\mathrm{N}_{2}-1000-6 \mathrm{~h}$, and He-1000-6h samples; (b) IR spectra of CHT and $\mathrm{N}_{2}-1000-6 \mathrm{~h}$ samples. 

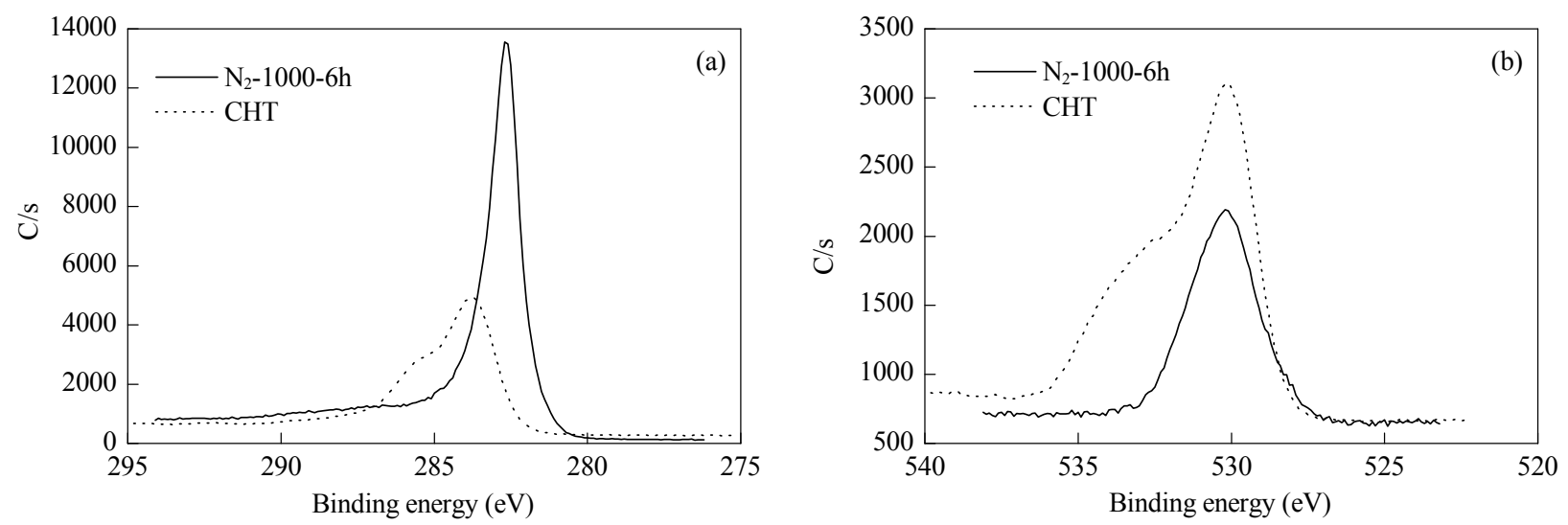

Fig. 7. C $1 s$ (a) and $01 s$ (b) XPS spectra of CHT and $\mathrm{N}_{2}-1000-6 \mathrm{~h}$ samples.

Table 3

Atomic concentration percentage of $01 s$ and C $1 s$ for both CHT and $\mathrm{N}_{2}-1000-6 \mathrm{~h}$ samples, evaluated by integration of the peaks.

\begin{tabular}{lcc}
\hline Sample & C 1s (at\%) & O 1s (at\%) \\
\hline CHT & 77.6 & 22.4 \\
$\mathrm{~N}_{2}-1000-6 \mathrm{~h}$ & 92.1 & 7.9 \\
\hline
\end{tabular}

presence of rather small ordered domains. These are characteristics rather interesting for catalytic applications, which are under investigation. The key in obtaining these properties is the thermal treatment in a flow of $\mathrm{N}_{2}$. It was demonstrated that the use of He rather than $\mathrm{N}_{2}$ does not allow to obtain the same results. The effect is attributed to the presence of traces of oxygen, enough to create the presence of oxygen functional groups on the surface at higher temperatures $\left(>750{ }^{\circ} \mathrm{C}\right)$, when graphitization occurs. These oxygen functional groups favor the graphitization process, while the oxygen concentration remains low to avoid the combustion of carbon.

\section{Acknowledgments}

The authors thank Dr. Francesca Bonino and Matteo Signorile of NIS Centre of Excellence and INSTM-University of Turin for their support and valuable discussion of Raman spectra

\section{References}

[1] Su D S, Perathoner S, Centi G. Chem Rev, 2013, 113: 5782

[2] Mleczko L, Lolli G. Angew Chem Int Ed, 2013, 52: 9372

[3] Vilatela J J, Eder D. ChemSusChem, 2012, 5: 456

[4] Su C, Loh K P. Acc Chem Res, 2013, 46: 2275

[5] Dreyer D R, Bielawski C W. Chem Sci, 2011, 2: 1233

[6] Dreyer D R, Jia H P, Bielawski C W. Angew Chem Int Ed, 2010, 49: 6813

[7] Schaetz A, Zeltner M, Stark W J. ACS Catal, 2012, 2: 1267

[8] Su C, Acik M, Takai K, Lu J, Hao S J, Zheng Y, Wu P P, Bao Q L, Enoki T, Chabal Y J, Loh K P. Nat Commun, 2012, 3:1298

[9] Centi G, Perathoner S. Catal Today, 2010, 150: 151

[10] Centi G, Perathoner S. ChemSusChem, 2011, 4: 913

[11] Bitter J H.J Mater Chem, 2010, 20: 7312

[12] Su D S, Schlögl R. ChemSusChem, 2010, 3: 136

[13] Umeyama T, Imahori H.J Phys Chem C, 2013, 117: 3195
[14] Centi G, Perathoner S. Eur J Inorg Chem, 2009, 26: 3851

[15] Centi G, Perathoner S. Coord Chem Rev, 2011, 255: 1480

[16] Su D S, Zhang J, Frank B, Thomas A, Wang X C, Paraknowitsch J, Schlögl R. ChemSusChem, 2010, 3: 169

[17] Yu D S, Nagelli E, Du F, Dai L M.J Phys Chem Lett, 2010, 1: 2165

[18] Sun XY, Wang R, Su D S. Chin J Catal (催化学报), 2013, 34: 508

[19] Yang Z, Nie H G, Chen X A, Chen X H, Huang S M. J Power Sources, 2013, 236: 238

[20] Zhang M, Dai L M. Nano Energy, 2012, 1: 514

[21] Zheng Y, Jiao Y, Jaroniec M, Jin Y G, Qiao S Z. Small, 2012, 8: 3550

[22] Powles R C, Marks N A, Lau D W M. Phys Rev B, 2009, 79: 075430

[23] Zhang J, Liu X, Blume R, Zhang A H, Schlögl R, Su D S. Science, 2008, 322: 73

[24] Liu X, Frank B, Zhang W, Cotter T P, Schlögl R, Su D S. Angew Chem Int Ed, 2011, 50: 3318

[25] Frank B, Zhang J, Blume R, Schlögl R, Su D S. Angew Chem Int Ed, 2009, 48: 6913

[26] Frank B, Blume R, Rinaldi A, Trunschke A, Schlögl R. Angew Chem Int Ed, 2011, 50: 1

[27] Cotarca L, Eckert H. Phosgenations-A Handbook. Weinheim: Wiley-VCH, 2003

[28] Mitchell C J, van der Borden W, van der Velde K, Smit M, Scheringa R, Ahrika K, Jones D H. Catal Sci Technol, 2012, 2: 2109

[29] Volodina V A, Kozlovskii A A, Kuzina S I, Mikhailov A I. High Energy Chem, 2008, 42: 311

[30] Zhang Z L, Wang Y H, Tan Q Q, Li D, Chen Y F, Zhong Z Y, Su F B. Nanoscale, 2014, 6: 371

[31] Meng Q N, Zhang F F, Wang L M, Xiang S Y, Zhu S J, Zhang G Y, Zhang K, Yang B. RSC Adv, 2014, 4: 713

[32] Chang B B, Guan D X, Tian Y L, Yang Z C, Dong X P. J Hazard Mater, 2013, 262: 256

[33] He G, Evers S, Liang X, Cuisinier M, Garsuch A, Nazar L F. ACS Nano, 2013, 7: 10920

[34] Yu X L, Wang J G, Huang Z H, Shen W C, Kang F Y. Electrochem Commun, 2013, 36: 66

[35] Xiao J P, Yao M G, Zhu K, Zhang D, Zhao S J, Lu S C, Liu B, Cui W, Liu B B. Nanoscale, 2013, 5: 11306

[36] Chang B B, Tian Y L, Shi W W, Liu J Y, Xi F N, Dong X P. RSC $A d v$, 2013, 3: 20999

[37] You C H, Liao S J, Li H L, Hou S Y, Peng H L, Zeng X Y, Liu F F, Zheng R P, Fu Z Y, Li Y W. Carbon, 2014, 69: 294

[38] Song X H, Wang Y B, Wang K, Xu R. Ind Eng Chem Res, 2012, 51: 13438

[39] Zhai D Y, Du H D, Li B H, Zhu Y A, Kang F Y. Carbon, 2011, 49: 725

[40] Fuertes A B, Alvarez S. Carbon, 2004, 42: 3049 


\section{Graphical Abstract}

Chin. J. Catal., 2014, 35: 869-876 doi: 10.1016/S1872-2067(14)60098-X

Low-temperature graphitization of amorphous carbon nanospheres

Katia Barbera*, Leone Frusteri, Giuseppe Italiano, Lorenzo Spadaro, Francesco Frusteri, Siglinda Perathoner, Gabriele Centi University of Messina and INSTM/CASPE, Italy; Eco-Rigen S.r.l. R\&D, Italy; Institute of Advanced Technologies for Energy "Nicola Giordano", National Council of Research (CNR), Italy

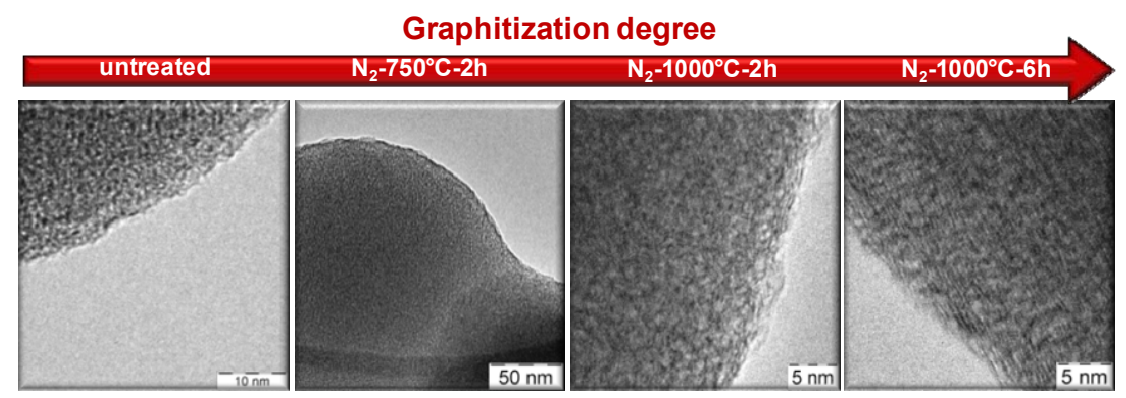

This study shows the possibility to graphitize amorphous carbon nanospheres, prepared by glucose carbonization, maintaining the round-shaped macro morphology, high surface area and porosity, and especially a large structural disorder in the graphitic layers stacking.

[41] Asaka K, Karita M, Saito Y. Appl Phys Lett, 2011, 99: 091907

[42] Sevilla M, Sanchis C, Valdes-Solis T, Morallon E, Fuertes A B. J Phys Chem C, 2007, 111: 9749

[43] Ramos A, Caméan I, Garcìa A B. Carbon, 2013, 59: 2

[44] Briston K J, Martin J M, Heau C, Martin M, Inkson B J. Nanotechnology, 2012, 23: 485602

[45] Sevilla M, Fuertes A B. Carbon, 2006, 44: 468

[46] Kasahara N, Shiraishi S, Oya A. Carbon, 2003, 41: 1654

[47] Frusteri L, Cannilla C, Barbera K, Perathoner S, Centi G, Frusteri F. Carbon, 2013, 59: 296

[48] Nieto-Marquez A, Espartera I, Lazo J C, Romero A, Valverde J L. Chem Eng J, 2009, 153: 211

[49] Genovese C, Ampelli C, Perathoner S, Centi G. J Energy Chem, 2013 22: 202

[50] Su D S, Centi G. J Energy Chem, 2013, 22: 151

[51] Thommes M. Chem Ing Technol, 2010, 82: 1059

[52] Jiang J X, Su F B, Trewin A, Wood C D, Campbell N L, Niu H, Dickinson C, Ganin A Y, Rosseinsky M J, Khimyak Y Z, Cooper A I.
Angew Chem Int Ed, 2007, 46: 8574

[53] Antonov D, Häußermann T, Aird A, Roth J, Trebin H-R, Müller C, McGuiness L, Jelezko F, Yamamoto T, Isoya J, Pezzagna S, Meijer J, Wrachtrup J. Mater Sci, 2013, arXiv:1303.3730

[54] Norfolk C, Kaufmann A, Mukasyan A, Varma A. Carbon, 2006, 44: 301

[55] Ungar T, Gubicza J, Ribarik G, Pantea C, Zerda W. Carbon, 2002, 40: 929

[56] Biscoe J, Warren B E. J Appl Phys, 1942, 13: 364

[57] Hays D, Patrick J W, Walker A. Fuel, 1983, 62: 1079

[58] Aminzadeh A. Appl Spectroscopy, 1997, 51: 817

[59] Stair P C. Adv Catal, 2007, 51: 75

[60] Ferrari A C, Robertson J. Phys Rev B, 2000, 61: 14095

[61] Chu P K, Li L H. Mater Chem Phys, 2006, 96: 253

[62] Ferrari A C, Rodil S E, Robertson J. Phys Rev B, 2003, 67: 155306

[63] Tang Z H, Zhang L Q, Zeng C F, Lin T F, Guo B C. Soft Matter, 2012, 8: 9214

[64] Yumitori S.J Mater Sci, 2000, 35: 139 